\title{
Expression of Cell Cycle Genes During Sesbania rostrata Stem Nodule Development
}

\author{
Sofie Goormachtig ${ }^{1}$, Marcio Alves-Ferreira ${ }^{1}$, Marc Van Montagu', Gilbert Engler ${ }^{2}$, and Marcelle \\ Holsters ${ }^{1}$ \\ ${ }^{1}$ Laboratorium voor Genetica, Department of Genetics, Flanders Interuniversity Institute for Biotechnology \\ (VIB), Universiteit Gent, K.L. Ledeganckstraat 35, B-9000 Gent, Belgium; 'Laboratoire Associé de I'In- \\ stitut National de la Recherche Agronomique (France), Universiteit Gent, B-9000 Gent, Belgium \\ Received 13 September 1996. Accepted 10 December 1996.
}

\begin{abstract}
Upon infection of Sesbania rostrata with Azorhizobium caulinodans, nodules are formed on roots and stems. Stem nodules develop from abundantly distributed dormant root primordia. To acquire more insight into the meristem organization during stem nodule development, the expression patterns of a mitotic B1-type cyclin gene (Sesro; CycB1;1), a cyclin-dependent kinase gene $(C d c 2-1 S r)$, and a histone $\mathrm{H} 4$ gene $(\mathrm{H} 4-1 \mathrm{Sr})$ of $\mathrm{S}$. rostrata were followed by in situ hybridization. $\mathrm{Cdc2-1Sr}$ transcripts were found in all cells of uninfected and infected root primordia. In uninfected root primordia, Sesro; $C y c B 1 ; 1$ transcripts were detected in a few cells of the apical root meristem whereas $\mathrm{H4}-1 \mathrm{Sr}$ transcripts were abundant in this region. Interestingly, after inoculation with $\mathrm{A}$. caulinodans, $\mathrm{H4-1Sr}$ transcripts disappeared in the root meristem and a patchy pattern of Sesro; $\mathrm{CyCB}$; 1 and $\mathrm{H4}-1 \mathrm{Sr}$ expression appeared in the cortex of the root primordium, reflecting the formation of globular nodule primordia. When bacterial invasion started, a distal nodule meristem was delimited wherein Sesro; $\mathrm{CycB} 1 ; 1$ and $\mathrm{H4}-1 \mathrm{Sr}$ expression was concentrated. Approximately 1 week after inoculation, meristem activity ceased, indicated by the loss of Sesro; $C y c B 1 ; 1$ and $\mathrm{H4}-1 \mathrm{Sr}$ expression.
\end{abstract}

The symbiosis between leguminous plants and bacteria of the genera Azorhizobium, Bradyrhizobium, Rhizobium, and Sinorhizobium (collectively called rhizobia) leads to the formation of new organs (nodules), inside of which differentiated bacteria fix atmospheric nitrogen. The nodules typically arise on roots; however, in some interactions stem-located nodules are also formed. A well-studied example is the tropical leg-

Corresponding author: M. Van Montagu, Laboratorium voor Genetica, Universiteit Gent, K.L. Ledeganckstraat 35, B-9000 Gent, Belgium. Fax: 32-9-2645349; E-mail: mamon@gengenp.rug.ac.be

Present address of M. Alves-Ferreira: Laboratório de Genética Molecular Vegetal, Universidade Federal de Rio de Janeiro, Rio de Janeiro, CEP 21944-370, Brasil.

Sofie Goormachtig and Marcio Alves-Ferreira have contributed equally to this work.

Nucleotide and/or amino acid sequence data are to be found at EMBL as accession numbers Z75660 and Z75661. ume Sesbania rostrata. As an adaptation to growth in waterlogged conditions $S$. rostrata carries dormant adventitious root primordia on several vertical rows along its stem. A root primordium can follow different developmental pathways depending on the growth conditions or external stimuli. When immersed in water, an adventitious root develops due to the activation of a distally located dormant root meristem (Duhoux and Dreyfus 1982). When internodal explants are cultured on basal medium, without growth regulators, shoot buds originate from a newly formed peripheral meristem (Spencer-Barreto and Duhoux 1994). Finally, upon infection with the microsymbiont Azorhizobium caulinodans ORS571, nodules appear due to the dedifferentiation of cortical cells at the base of the root primordium (Tsien et al. 1983; Duhoux 1984; Dreyfus et al. 1988). Stem nodulation is basically similar to root nodulation, but presents distinct advantages for the study of the early stages of nodule development because of the special topology, abundance, and predetermined nature of the nodulation sites (Goormachtig et al. 1995).

Depending on the legume species, mature nodules are either determinate or indeterminate (Newcomb et al. 1979). Indeterminate nodules occur mostly on temperate legumes, such as pea and alfalfa, and have a cylindrical form due to a persistent apical meristem. They develop in a distal-proximal direction and mature nodules contain different zones, each characterized by specific gene expression (Newcomb 1976; Franssen et al. 1992). Determinate nodules occur on tropical legumes, such as bean and soybean, Lotus, and S. rostrata, are spheri$\mathrm{cal}$, and have no persistent meristem. The central tissue cells of determinate nodules were thought to pass simultaneously through the same developmental stages (Newcomb et al. 1979). However, it has recently been shown that in common bean a gradient exists in the establishment of infected plant cells (Taté et al. 1994; Patriarca et al. 1996). Also, for developing root nodules of $S$. rostrata the occurrence of radial differentiation zones was described (Ndoye et al. 1994).

Stem nodule development on $S$. rostrata has previously been studied with light and electron microscopy (Tsien et al. 1983; Duhoux 1984). The nodulation sites are adventitious root primordia that protrude through the stem cortex and epidermis, creating a circular fissure (Fig. 1A). The root primordia have a central vascular bundle, connected to the vascular system of the stem, and a dormant apical meristem (Fig. 1A, 
white spot). No root hairs are present and bacterial infection occurs by crack entry. Upon inoculation with A. caulinodans ORS571, bacteria multiply in the circular fissure, colonizing intercellular spaces to form densely populated infection pockets (Fig. 1B and C). Opposite to the infection pockets, middle and inner cortical cells dedifferentiate and divide, forming nodule primordia (Fig. 1B and C). From the infection pockets, infection threads grow toward the nodule primordia and bacteria start to invade the cells of the primordia.

To acquire more insight into the cell proliferations and differentiations triggered by bacterial infection, we studied the expression pattern of several cell cycle-related genes by in situ hybridization. Central in the control of the eukaryotic cell cycle are the cyclin-dependent kinases (CDKs) (for a review, see Pines 1994; Jacobs 1995; Nigg 1995). The cell cycle stage-

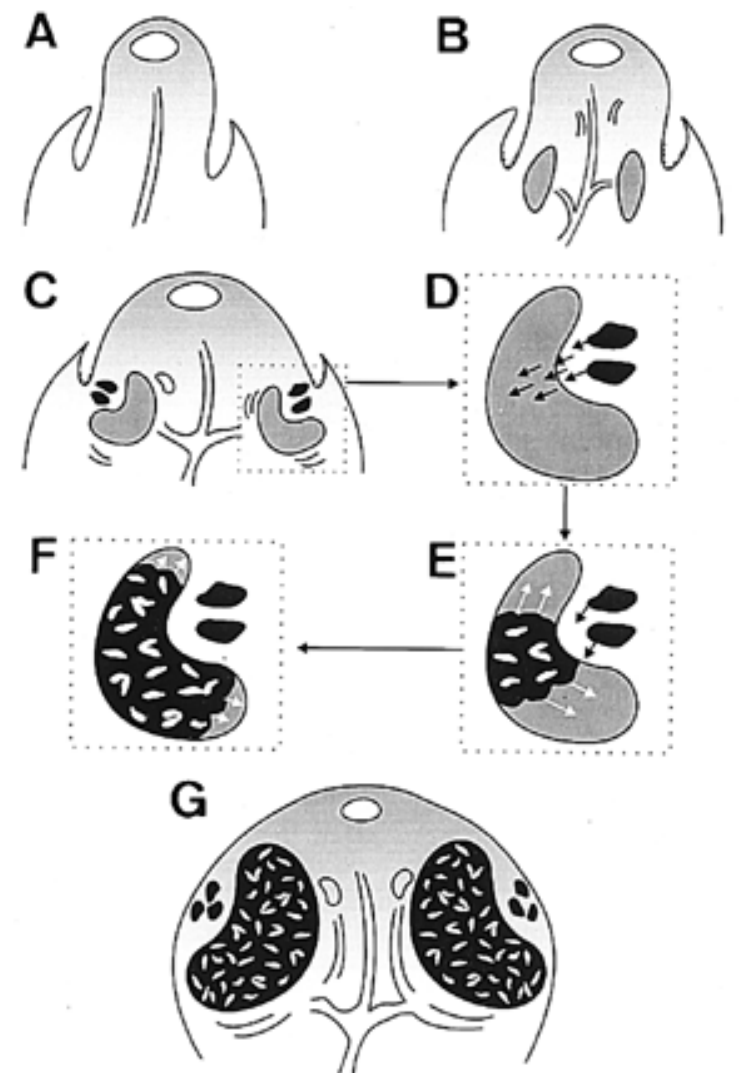

Fig. 1. Development of Sesbania rostrata stem nodules. Drawing represents medial longitudinal sections of various developmental stages and combines data obtained by various microscopical techniques published previously (Tsien et al. 1983; Duhoux 1984) with results from in situ hybridizations presented here. A, Uninfected root primordium. At apical part, dormant root meristem is present (visualized as white spot). B, After infection (2 days), bacteria multiply in fissure (small black dots) and nodule primordia are formed (gray regions). Also, first elements of nodule and connecting vascular bundles are laid down (parallel lines). Per root primordium, most often two nodule primordia develop. $\mathbf{C}$, Nodule primordia (gray regions) surround infection pockets (black spots), approximately 3 days after inoculation. Open spot flanking central tissue corresponds to transversal sections of vascular bundles. D-F, Enlargement of a nodule primordium. Arrows indicate direction of bacterial invasion. White dots in central region show uninfected cells between infected ones (black labeled). G, Young nodule, approximately 8 days after infection. Central tissue completely differentiated; nodule grows further via cell enlargement. specific activity and the specificity of the CDKs are mainly determined by the binding with different cyclins. For example, progression through the $\mathrm{G}_{2}-\mathrm{M}$ phase requires the formation of a complex between the $\mathrm{p} 34^{\mathrm{cdc} 2}$ kinase and a mitotic cyclin (for a review, see Pines 1994; Nigg 1995). Most of the cyclins function only during specific stages of the cell cycle. This cyclic activity is determined by cell cycle stage-dependent transcription (Amon et al. 1993; Shaul et al. 1996) and by a mechanism of timed destruction (Glotzer et al. 1991; Tyers et al. 1992). Several plant cyclin and CDK gene homologs have been isolated (for a review, see Jacobs 1995). In addition to most cyclins, histones also show a cell cycle stage-dependent appearance, with preferential expression during the DNA synthesis (S) phase (Mikami and Iwabuchi 1993). Thus, mitotic cyclin genes and histone genes are good molecular markers for cells that are dividing. Here, we describe the meristem organization during the development of stem nodules of $S$. rostrata by examining the expression patterns of a B1-type cyclin, a $c d c 2$, and a histone $\mathrm{H} 4$ gene homolog of $S$. rostrata.

\section{RESULTS}

\section{Isolation of a cyclin and a $c d c 2$ homolog of Sesbania rostrata.}

RNA from developing stem nodules was used in reverse transcription-polymerase chain reactions (RT-PCRs) with degenerate primers derived from amino acid sequence motifs of different mitotic cyclins or $\mathrm{Cdc} 2$ proteins (for details, see Materials and Methods; Fig. 2). A nested RT-PCR with primers covering three conserved regions of cyclins resulted in a DNA fragment of the expected size (294 bp). Screening of a developing stem nodule cDNA library (see Materials and Methods) with this probe, yielded several positive clones, the largest containing an incomplete 955-bp cDNA insert (pCyccd). A full-length cDNA clone $(1,632 \mathrm{bp})$ was isolated with the $5^{\prime}$ rapid amplification of cDNA ends (RACE) method (see Materials and Methods) and encoded an open reading frame (ORF) of 445 amino acids preceded by an in-frame stop codon. Besides the cyclin box in the $\mathrm{C}$ terminus, the cyclin held a destruction box motif in the $\mathrm{N}$ terminus (Fig. 2A) (Renaudin et al., in press; Renaudin et al. 1996).

RT-PCR with degenerate primers covering the conserved PSTAIR motif and the catalytic kinase domain of Cdc2 homologs resulted in a band of the expected size $(270 \mathrm{bp})$ that comprised two types of sequences differing in 14 nucleotides (giving rise to one amino acid substitution Val-Ser; Fig. 2B). Screening of the cDNA library resulted in 10 positive clones, all corresponding to the same PCR fragment. The largest clone contained a full-length cDNA of 1,227 bp with an ORF of 295 amino acids preceded by an in-frame stop codon (Fig. 2B). The Sesro; $C y c B 1 ; 1$ and $C d c 2-1 S r$ sequences are deposited in the EMBL data bank (accession numbers $\mathrm{Z75660}$ and Z75661, respectively). The $S$. rostrata histone $\mathrm{H} 4$ was obtained by screening the cDNA library under low-stringency conditions with the pea histone $\mathrm{H} 4$ homolog as a probe (Goormachtig et al 1996).

\section{Primary structure of the Sesbania rostrata cyclin and Cdc2 proteins.}

Data base searches (EMBL, GenBank, and Swissprot data banks) revealed that the $S$. rostrata cyclin was approximately 
atcgCattcicgttcattci.

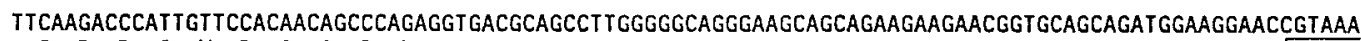

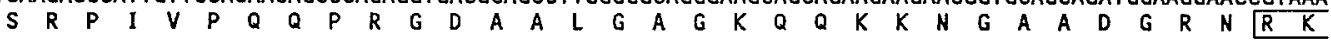
GCACTTGGTGATATTGGAAACTIGGTCACTGTAAGAGGAGT TGAGGTCAAGCCTAATCGTCCCATCACAAGGAGTTTCTGTGCCCAACTACTTGCCAATG

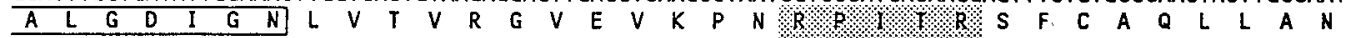
CACAAGCTGCAGCTGCTGCTGAAAATAACAAGAAACAGGCTTGTCCCAATGTGGCTGGGCCTCCTCCTGTTGTTGAAGGAGTTGCAGTGGCTAAAAGAGT A Q A A A A A GGCCCCCAAACCAGGTCAGAAGAAAGTCACCACAAAACCAAAGCCTGAGGAAGTCATTGAAATAAGTCCAGACGAAGAGGTCCACAAAGACAATAATAAG $\begin{array}{llllllllllllllllllllllllllllllllllllll}A & P & K & P & G & Q & K & K & V & T & T & K & P & K & P & E & E & V & I & E & I & S & P & D & E & E & V & H & K & D & N & N & K\end{array}$ AAAAAGGAAGGTGATGCCAACACCAAGAAGAAATCACACACTTATTCTTCTGTGCTCACAGCTCGAAGCAAGGCAGCATGTGGTCTGACTAATAAACCTA $K$ K K $E$ E G AAGAGATTATTGACATTGATGCTGCTGACACTGCCAATGAGCTTGCTGCTGTGGAATATATTGAAGACATTTACAAATTCTATAAAATGGTTGAGAATGA K E E I I I AAGCCGTCCCCATGACTACATGGACTCACAACCTGAGATCAATGAGAGGATGAGAGCTATACTTGTTGATTGGCTGATAGATGTACACAGCAAATTTGAC $\begin{array}{llllllllllllllllllllllllllll}S & R & P & H & D & Y & M & D & S & Q & P & E & I & N & E & R & M & R & A & I & L & V & D & W & L & I & D & V\end{array}$ CIITCACTIGAAACCCTITAITTGACCATCAACATAGITGATAGGTTCITAGCAGTTAAGACTGIGCCAAGGAGGGAACTGCAATTGGTTGGCATCAGTG

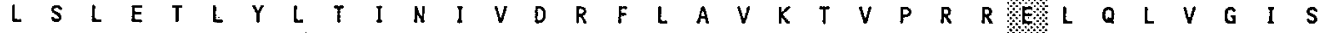
CCATGCTGATGGCATCCAAGTATGAAGAAATCTGGCCCCCAGAGGT TAATGACTTTGTCTGCCTCTCAGACAGAGCTTACACTCATGAACAGATACTTTT

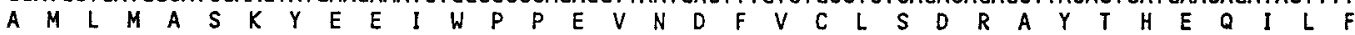
CATGGAGAAAATCATATTGGGGAAGCTAGAATGGACCTTGACTGTGCCTACCCCTTITGTTTTCCTAGTTCGTITTATCAAGGCATCAGTGCCAGATGAG

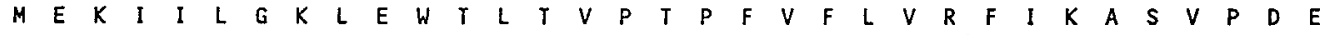
GCATTGGAAAACATGGCACATTTCCTITCTGAATTGGGGATGATGCATTATGCCACCTTAATGTATIGTICATCAATGGTTGCTGCCTCAGCAGTCTATG A L $L$ E N M A CTGCAAGATGCACTCTGAATAAGAGCCCTGTTTGGAATGAGACACTTAAGCAGCACACTGGTTACTCTGAAGAACAACTTATGGATTGTGCTAGACTACT

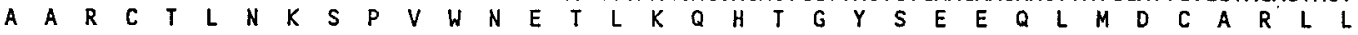
GGTGAGCTTGCACTCCACAGT TGGGAATGGGAAGCTTAAGGTTGTGTATAGAAAGTACTCTGATCCTGAGAGAGGATCTGTTGCAGTGCTTCCACCGGCT $V$ S L H S T V G N G K L K V V Y R. K Y S D P E R G S V A V L P P A AAAAATCTTCTGTCTGAAGGGAAGAGCCTCTAAAGITTGACATAGAAAAGCAGCCACAAGCAAGTATTGAGTTTAATGTGGGATTCTGCAATAACCATIT K N L L S E G K S L * GTTATTGTATTTITTTITAATCTITITTCTATAAGCCATTTGTAGTAGGT TGAAGGAATCAATTTATAGCTACTIITAAATGGCAATAACAACTTICATT IGCTATTGIITTAAAAAAAAAAAAAAAAAAAA

B

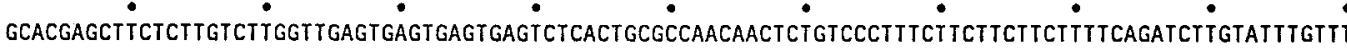
ACTCAATTTCCCTCTTAAGTCTCTTAGCTTTCAACTGAGACTTTGTTCCATGGAACAGTACGAGAAGGTCGAGAAGATTGGCGAAGGAACATACGGCGTC $M$ M O Y E K V E K I G E G T GTITATAAGGCCCGCGACCGCGTCACCAATGAGACCATCGCTCTCAAGAAAATTCGCCTCGAGCAAGAGGACGAAGGGGTTCCCAGCACCGCCAT:CG

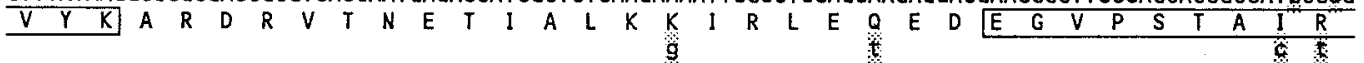
AGATTTCTCTCTTGAAAGAAATGCAGCATAGGAACATTATTAGGITGCAÖGATGTAGTGCACAGCGGGAAGCGATTGTATCTGGITITTGAGTA:CT.gGA

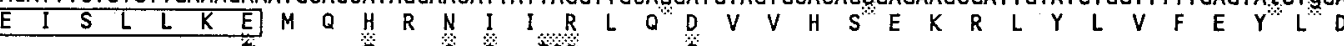
Q $\mathrm{O}$ \%

CTTAGATCTAAAGAAGCACATGGATTCÖTCTCCTGGAOTTT

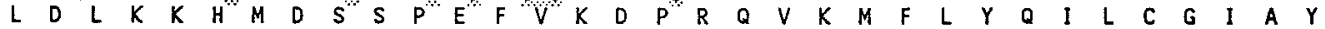
TGTCATTCACATAGAGTICTICACCGAGACTTGAAACCACAGAATTTGT TGATAGATCGCCGTACTAATTCACTAAAGCTTGCAGATITTGGATIGGCTA

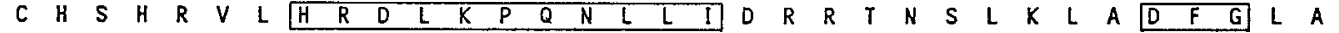
GGGCATITGGCATICCTGTCAGGACATITACACATGAGGTTGTCACACTGTGGTACAGAGCTCCAGGCATATTGCTTGGATCTCGTCATTATTCTACCCC $\begin{array}{llllllllllllllllllllllllllllllllllllllllll}R & A & F & G & I & P & V & R & T & F & T & H & E & V & V & T & L & W & Y & R & A & P & G & I & L & L & G & S & R & H & Y & S & T & P\end{array}$ AGTTGATATCTGGTCAGTGGGATGTATATITGCAGAGATGGTAAACCGACGGCCTCTATTCCCTGGTGACTCTGAGATTGATGAATTGTTTAAAATATTC

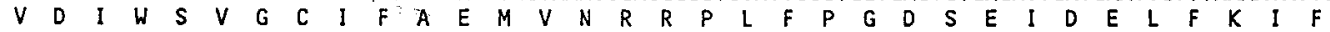
AGAATCTTGGGTACACCAAATGAAGATACATGGCCCGGAGTAACTTCATIGCCTGATTTTAAATCAACATITCCCAAGTGGCCACCTAAGGATCTAGCAA $\begin{array}{llllllllllllllllllllllllllllllll}R & I & L & G & T & P & N & E & D & T & W & P & G & V & T & S & L & P & D & F & K & S & T & F & P & K & W & P & P & K & D & L\end{array}$ CTGTGGITCCAAATCTYGAGCAAGCTGGTCTTAATCTTCTTTCTAGTATGCTITGCTTGGATCCCAGCAAAAGAATTACCGCCAGGAGCGCTGTGGAGCA

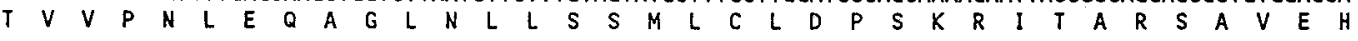
TGAATACTTCAAAGACATTAAATTTGTACCCTGATTCCATATCTTCATGGCCAAGGTGTITATAGTAATATGTICAGAATITATGGGTTIYGACTATGCG

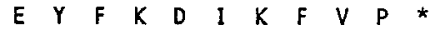
AGAAATGCGTTCTATCTTTGCTCTITTCTICAATGACTIGGGGCTGTCATATTTCAATITTTTGTCCTTGCCAATAITTCAGAATCAACTTGAGTGTGGA AAAAAAAAAAAAAAAAAAAAAAAAAAA

Fig. 2. A, DNA sequence of Sesro; $C y c B 1 ; 1$. Arrows indicate sense and antisense primers used for reverse transcription-polymerase chain reaction (RT-PCR, see Materials and Methods). Open box indicates destruction box (see text). Gray boxes correspond to typical primary structure features, discussed in text. Amino acids between braces considered to be the cyclin core. B, DNA sequence of $C d c 2-1 S r$. Arrows indicate primers used for RT-PCR (see Materials and Methods). Open boxes correspond to typical CDK traits (see text). Gray boxes indicate 14 different nucleotides between the two $c d c 2$ PCR fragments. 
90 and $80 \%$ similar with the soybean cyclins S13-6 and S13-7 (Hata et al. 1991) and with the tobacco Ntcyc29 (Setiady et al. 1995) and the Anthirrhinum Amcy11 cyclins (Fobert et al. 1994), respectively. Recently, Renaudin et al. (Renaudin et al., in press; Renaudin et al. 1996) have proposed to divide plant mitotic cyclins into two groups, the CycA group consisting of three subgroups (CycA1, CycA2, and $\mathrm{CycA} 3$ ) and the $\mathrm{CycB}$ group consisting of two subgroups ( $\mathrm{CycB} 1$ and $\mathrm{CycB} 2)$. According to the criteria defined by these authors, the $S$. rostrata cyclin had all the features of the $\mathrm{CycB} 1$ subgroup and was named Sesro; $C y c B 1 ; 1$. Indeed, the HSKF (amino acids 231 to 234) and RPITR (amino acids 55 to 59) sequences corresponded with the typical B-type signature (H/Q)-K/R/Q)$(\mathrm{F} / \mathrm{L})$ and to the RP-TR consensus, respectively. Moreover, the presence of an arginine (R; amino acid 419) in front of the $\mathrm{KY}$ sequence at the end of the cyclin core is considered to be a typical B-trait. Classification into the B1 subgroup was based on the conserved motif SSVLTARSKAAC (amino acids 151 to 162$)$ and the acidic glutamic acid (E) at position 261. Also, the destruction box showed a typical CycB1 structure: an aspartic acid (D) was present in the sixth position and a conserved asparagine $(\mathrm{N})$ in the last position.

Data base searches with the $S$. rostrata Cdc2-1Sr-deduced amino acid sequence revealed $99 \%$ similarity with the Cdc2S5 protein from soybean (Miao et al. 1993) and with the Cdc2

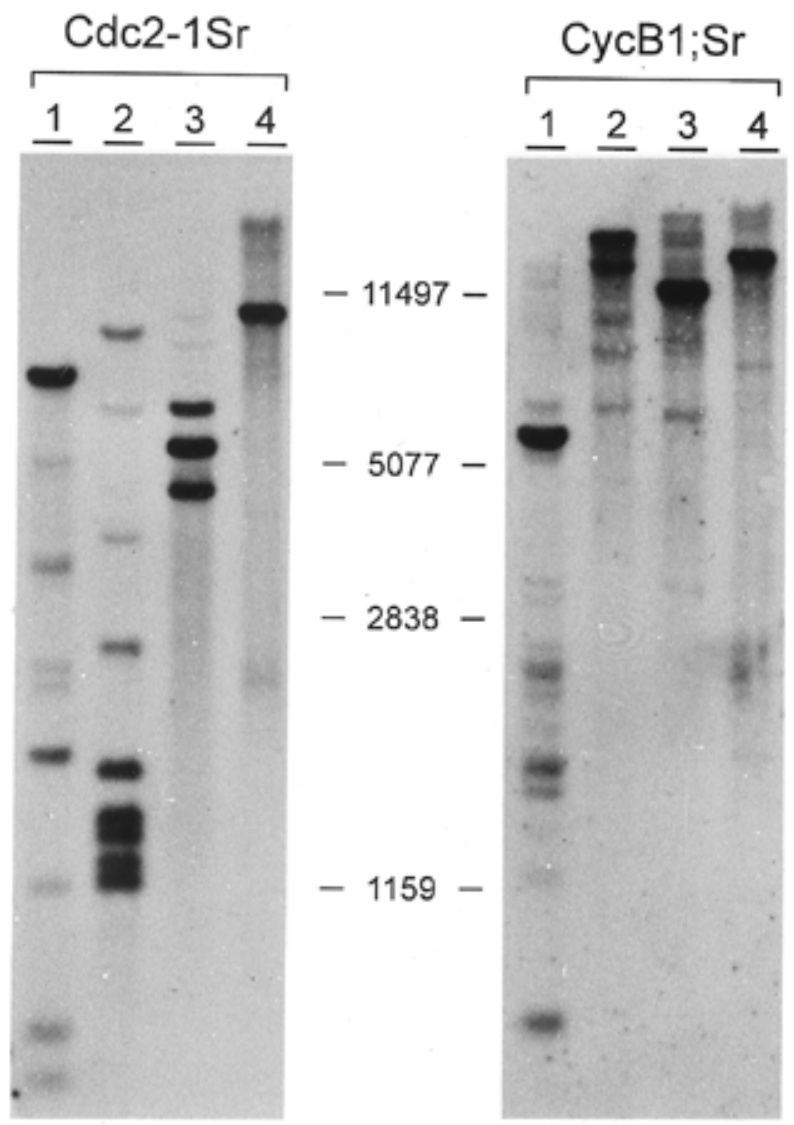

Fig. 3. Southern blot analysis of $C d c 2-1 S r$ and Sesro;CycB1;1 (CycB1;Sr). For both panels, lane 1, HindIII-digested DNA; lane 2, EcoRI-digested DNA; lane 3, XbaI-digested DNA; lane 4, PstI-digested DNA. kinase from Vigna aconitifolia (Hong et al. 1993); 96\% similarity was found with the other $\mathrm{Cdc} 2$ homolog (Cdc2-S6) from soybean (Miao et al. 1993). The Cdc2-1Sr amino acid sequence presents the typical structural features of $\mathrm{Cdc} 2$ proteins (Hanks et al. 1988), such as the glycine-rich loop of the ATP-binding site (GEGTYGVVYK; amino acids 11 to 20; Fig. 2B), the 16-amino-acid, highly conserved PSTAIR region (amino acids 42 to 57; Fig. 2B), and the domains typical for serine/threonine protein kinases (HRDLKPQNLLI at position 125 to 135 and DFG at position 146 to 148 ; Fig. 2B) (Hanks et al. 1988).

\section{Genomic organization of the Sesro; $C y c B 1 ; 1$ and $C d c 2-1 S r$ genes.}

$S$. rostrata genomic DNA was digested with four different enzymes and hybridized with probes derived from the inserts of pCdc2-1 or pCyc-cd (see Materials and Methods) (Fig. 3). Sesro; $C y c B 1 ; 1$ belonged to a multigene family because several bands were detected on the Southern blot, even after stringent washes.

The $C d c 2-1 S r$ probe hybridized mainly with one band on HindIII- and PstI-digested genomic DNA and with several bands when $S$. rostrata genomic DNA was cut with EcoRI and $X b a \mathrm{I}$. Because the fragment used as probe (see Materials and Methods) did not contain restriction sites corresponding to the latter enzymes, the observed pattern could be due either to the presence of the restriction sites within introns or to the presence of very related $\mathrm{Cdc} 2$ homologs. The latter interpretation is very plausible as two different, but highly related, Cdc2 sequences were found within the PCR-amplified fragment. Also, other, less related $c d c 2$ genes exist in $S$. rostrata because in all restriction digests faint bands were detected even under high stringency hybridization conditions.

\section{Expression pattern of the Sesro; $C y c B 1 ; 1, C d c 2-1 S r$, and $\mathrm{H4}-1 \mathrm{Sr}$ genes during stem nodule development.}

To study the development of the $S$. rostrata stem nodules, in situ hybridizations were performed with Sesro; $C y c B 1 ; 1$, $\mathrm{Cdc} 2-1 \mathrm{Sr}$, and histone $\mathrm{H} 4-1 \mathrm{Sr}$ as probes. Antisense, ${ }^{35} \mathrm{~S}-$ labeled RNA probes were hybridized against $10-\mu \mathrm{m}$ sections of noninfected and infected root primordia (see Materials and Methods). After hybridization and counter-staining with toluidine blue, photographs were taken with dark-field optics (signals seen as white dots), bright-field optics (signals seen as black dots), or the double-exposure method (signals seen as red dots).

In uninfected, adventitious root primordia, cyclin transcripts were detected in a few cells of the apical root meristem (Fig. $4 \mathrm{~A}$ and $\mathrm{B}$ ). In contrast, $\mathrm{H} 4-\mathrm{SSr}$ transcripts were found in many cells of the apical root meristem and also in some cortical cells (Fig. 5A and F).

One day after bacterial inoculation, both Sesro; $C y c B 1 ; 1$ and $H 4-1 S r$ transcripts were present in highly vacuolated cortical cells scattered over the root primordium (Fig. 4C and D; Fig. $5 \mathrm{~B}$ and $\mathrm{G}$ ) and in cells flanking the central vascular system (Fig. 4C and D, arrow; Fig. 5B and G, arrow). The abundant expression of $\mathrm{H} 4-\mathrm{SSr}$ in the apical root meristem, as detected in uninfected root primordia, was no longer observed (Fig. 5B, $\mathrm{C}, \mathrm{G}$, and $\mathrm{H}$ ).

Two days after infection, globular nodule primordia were observed, consisting of small cytoplasmically dense cells that 
express both Sesro; $C y c B 1 ; 1$ and $H 4-1 S r$ genes (Fig. 4E; Fig. $5 \mathrm{C}$ and $\mathrm{H}$ ) in a patchy pattern, typical for cell cycle phaserelated genes. In longitudinal sections, often two nodule primordia in a symmetric arrangement were observed. However, occasionally only one primordium was seen (Fig. 5D and I). The nodule primordia developed from inner/middle cortical regions (e.g., Fig. 4E).
Three days after infection (Fig. 4F; Fig. 5D, E, I, and J), the globular nodule primordium changed into a $360^{\circ}$ open basket structure (apple shape) around the infection centers, as was described for the $S$. rostrata root nodules (Ndoye et al. 1994). The primordium (Fig. 4F; Fig. 5D, E, I, and J) as well as the surrounding developing vascular tissues (Fig. 4F, arrows) showed Sesro; $C y c B 1 ; 1$ and $H 4-1 S r$ expression. At higher
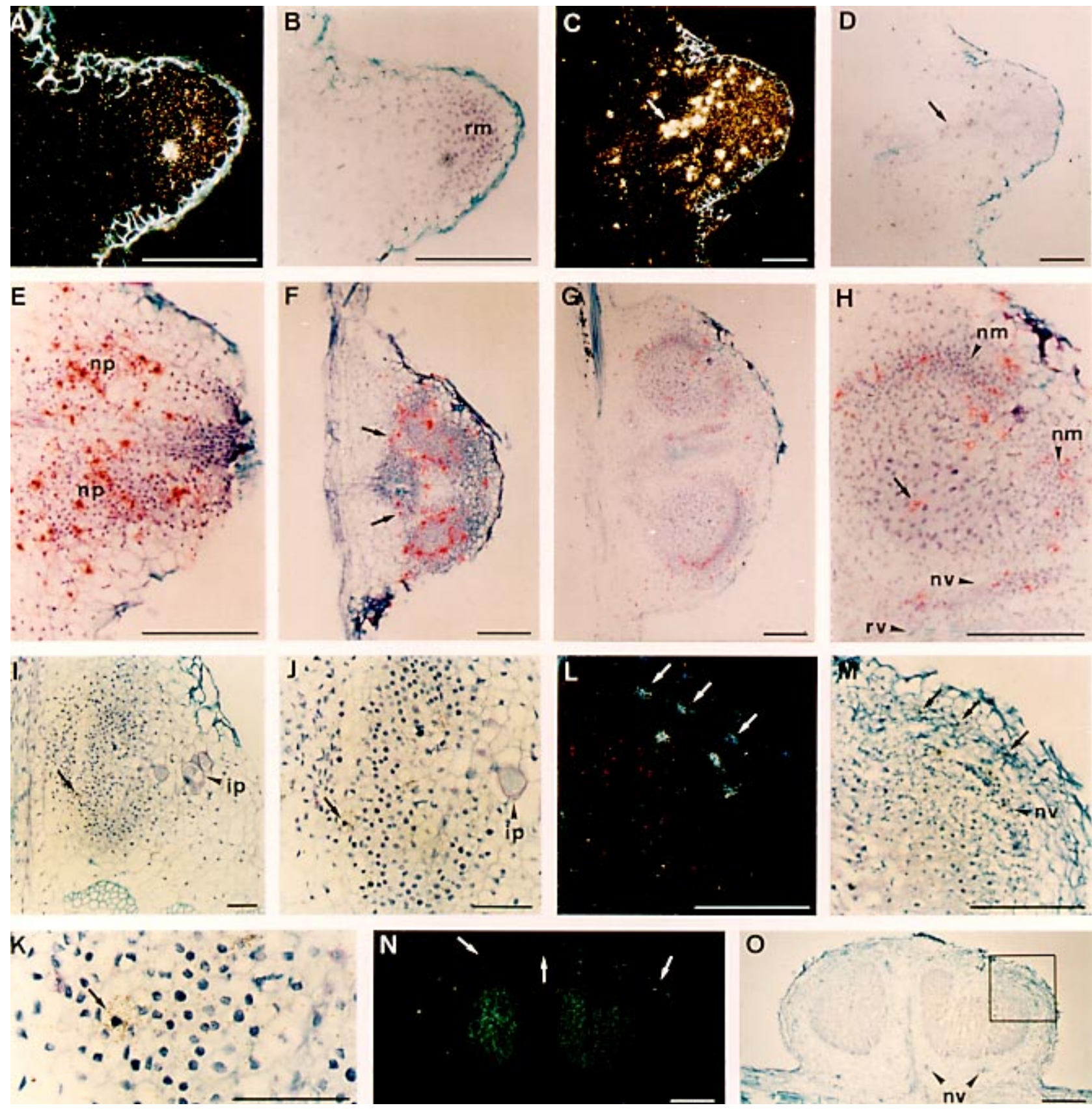

Fig. 4. In situ localization of Sesro; $C y c B 1 ; 1$ during stem nodule development. A-B, Dark- and bright-field micrographs of longitudinal section of uninfected root primordium. C-D, Dark- and bright-field micrographs of longitudinal section of dormant root primordium, 1 day after bacterial infection. Arrow indicates cells that flank vascular bundle and contain cyclin transcripts. E-G, Double-exposed micrographs of longitudinal sections of root primordium infected for 2, 3, and 4 days, respectively. H, Enlargement of upper part of panel $\mathbf{G}$. Arrow indicates infected cell that expresses cyclin gene. I$\mathbf{K}$, Section of a butyl methacrylate-embedded developing nodule (infected for 3 days). Arrow indicates cell entering mitosis. L-O, Dark- and bright-field micrographs of a longitudinal section of a young nodule (8 days). L-M, Enlargements of region indicated as rectangle in panel $\mathbf{O}$. Arrows indicate peripheral tissue cells expressing cyclin gene. Abbreviations: ip, infection pocket; nm, nodule meristem; np, nodule primordium; nv, nodule vascular tissue; rm, root meristem; rv, vascular bundle of root primordium. Bars $=150 \mu \mathrm{m}(\mathbf{A}-\mathbf{G}, \mathbf{L}-\mathbf{O})$ and $=50 \mu \mathrm{m}(\mathbf{I}-\mathbf{K})$. 
magnification (Fig. 5E and J), infection threads (orange dots and stripes in dark field; Fig. 5E, arrows) were observed that guide the bacteria from the infection pockets to the primordium cells. More cytological details could be seen in a longitudinal section of a methacrylate-embedded nodule hybridized with a Sesro; $C y c B 1 ; 1$ antisense RNA probe (Fig. 4I$\mathrm{K})$. High magnification showed a cell entering mitosis and expressing the cyclin gene (Fig. 4K, arrow).
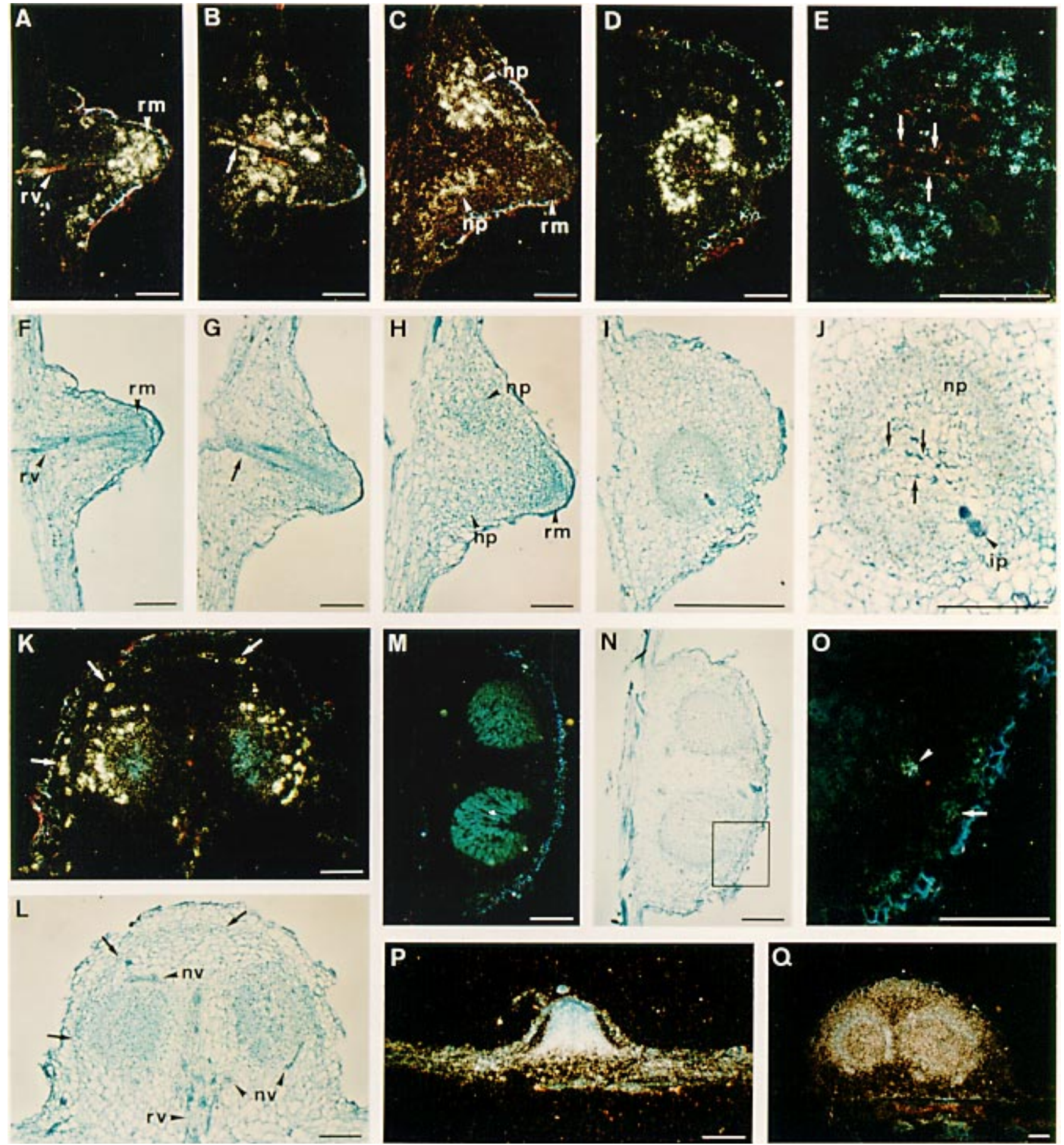

Fig. 5. A-L, In situ localization of $H 4-1 S r$ during stem nodule development. A-D, Dark-field micrographs of longitudinal sections of uninfected and infected root primordium at 1,2, and 3 days post inoculation, respectively. Arrow in $\mathbf{B}$ indicates cells around vascular bundle of root primordium expressing H4-1Sr. E, Enlargement of nodule primordium of D. Arrows indicate infection threads. F-J, Bright-field micrographs corresponding to A-E, respectively. K-L, Dark- and bright-field micrographs of longitudinal section of developing nodule, 4 days after infection. Arrows indicate peripheral tissue cells expressing H4-1Sr. M-N, Dark- and bright-field micrograph of a young nodule (8 days). O, Magnification of M. Arrows in M-O indicate same as arrows in $\mathbf{K}$ and $\mathbf{L}$. Arrowhead indicates residual, peripheral, meristematic cell expressing histone gene. P-Q, Dark-field photographs of longitudinal section of uninfected and infected (4 days) root primordium, respectively, hybridized with a $C d c 2-1 S r$ antisense probe. Abbreviations as in Figure 4. Bars $=150 \mu \mathrm{m}$. 
In further stages of development (day $4,5,6, \ldots$ ), zonation took place in the central tissue (Fig. $4 \mathrm{G}$ and H; Fig. $5 \mathrm{~K}$ and L) and Sesro;CycB1;1 and $H 4-1 S r$ expression became concentrated in more distal-peripheral regions, whereas the most proximal cells (closest to the stele of the original root primordium) started to be invaded by bacteria (recognizable by light-blue stained cytoplasm; Fig. 4H; Fig. 5K and L). A few infected cells still expressed the Sesro; $C y c B 1 ; 1$ and $H 4-1 S r$ genes (Fig. 4H, arrow). In Figure $4 \mathrm{H}$, a developing nodule vascular (nv) bundle is visible, showing Sesro; $C y c B 1 ; 1$ expression.

Eight days after infection, expression of Sesro; $C y c B 1 ; 1$ and $H 4-1 S r$ was restricted to a few distally located cells of the central tissue (Fig. 5M-O, arrowhead). Higher magnification of this region showed that the external layers became infected (infection threads with an orange-brown color in dark field; Fig. 4L).

In the later stages of development (from day 4 on), cells in a concentric zone of the nodule cortex expressed both the cyclin and histone homologs (Fig. 4L-O, arrows; Fig. 5K-O, arrows). The cells of this layer were small and slightly flattened (see Figure 4L and M). Finally, in mature nodules, $\mathrm{H4}-1 \mathrm{Sr}$ and Sesro; $C y c B 1 ; 1$ expression could no longer be detected (data not shown).

Sections corresponding to different stages of stem nodule development were also hybridized with a $C d c 2-1 S r$ antisense probe. A basal homogenous $c d c 2$ expression was detected in all cells (meristematic and cortical) of a noninfected root primordium and in developing nodules (Fig. 5P and Q).

\section{DISCUSSION}

Stem nodulation on $S$. rostrata was used as a model system to study early stages of nodule development. To describe the process in molecular terms, we studied the expression patterns of cell cycle-related markers with in situ hybridizations.

A $c d c 2$ and a cyclin gene homolog were isolated with a PCR approach. The PCR-amplified $c d c 2$ band contained two closely related sequences. A full-length cDNA clone was isolated corresponding to one of the two PCR fragments $(C d c 2$ $1 S r)$. The $C d c 2-1 S r$-deduced amino acid sequence showed all the characteristics of the $\mathrm{Cdc} 2$ protein family. The other gene still has to be characterized and it remains to be determined whether the two $S$. rostrata $c d c 2$ genes are differentially expressed. In soybean and pea, two highly related functional $c d c 2$ homologs were found (Miao et al. 1993; Franssen et al. 1994) and for soybean it was shown that only one was induced during nodulation (Miao et al. 1993). Based on criteria proposed by Renaudin et al. (Renaudin et al., in press; Renaudin et al. 1996), the $S$. rostrata cyclin homolog belongs to the B1 subgroup of mitotic plant cyclins, some members of which were shown to function during $\mathrm{G}_{2}-\mathrm{M}$ transition (Fobert et al. 1994; Setiady et al. 1995).

The $C d c 2-1 S r$ gene turned out to be of little use as a marker for nodule development. In situ hybridizations with the $C d c 2$ $1 S r$ probe revealed expression all over the adventitious root primordia. The cortical cells as well as the apical dormant root meristem showed a basal, homogenous expression level. No induction or stronger expression was observed upon bacterial inoculation. This is in contrast to pea and alfalfa root nodulation, in which $c d c 2$ transcripts were not detected in the inner cortical cells before bacterial infection (Yang et al. 1994). The overall $c d c 2$ expression may reflect the immature and totipotent character of the adventitious root primordia (Tsien et al. 1983; Duhoux 1984; Spencer-Barreto and Duhoux 1994). Also, young, protruding, lateral roots of radish and Arabidopsis exhibit $c d c 2$ expression in all cells (Martinez et al. 1992; Hemerly et al. 1993); therefore, regarding the expression of $c d c 2$, lateral and adventitious root primordia seem to be very similar.

In contrast to the $C d c 2-1 S r$ gene, the $S$. rostrata cyclin and the histone genes were helpful molecular markers to follow nodule development. Before bacterial inoculation, hardly any mitotic cyclin expression was observed in the adventitious root primordia. Only a few cells of the apical meristem contained Sesro; $C y c B 1 ; 1$ transcripts, indicating very low division activity and confirming the observed null-mitotic index in this tissue (Spencer-Barreto et al. 1995). Histone H4- $\mathrm{Sr}$ transcripts on the contrary were very abundant in the apical root meristem. Accumulation of $\mathrm{H} 4$ transcripts has been reported as a typical DNA synthesis (S) phase event (Mikami and Iwabuchi 1993); therefore, it seemed plausible to ascribe the discrepancy in expression between the two cell-cycle markers to an arrest in $\mathrm{S}$ phase or to endoreduplication. In the latter case, cells with a double DNA content should be present in the tissues that harbor the $\mathrm{H} 4-\mathrm{ISr}$ transcripts. Using flow cytometry, Spencer-Barreto et al. (1995) observed a 2C DNA content in the meristem cells of the adventitious root primordia of $S$. rostrata and proposed that the majority of the cells of the apical meristem are arrested in $\mathrm{G}_{0}-\mathrm{G}_{1}$. Therefore, endoreduplication is improbable and the accumulation of $\mathrm{H} 4-1 \mathrm{Sr}$ transcripts is more likely to reflect an arrest in early $\mathrm{S}$ phase. Perhaps, it is a preparation for massive histone $\mathrm{H} 4$ protein synthesis and fast division response to allow rapid adventitious root growth upon waterlogging.

In contrast to cyclin transcripts, $\mathrm{H} 4-1 \mathrm{Sr}$ transcripts were also detected in a few cortical cells of the root primordia. Perhaps these cells undergo endoreduplication. Preliminary evidence from confocal microscopy of 4',6-diamidino-2-phenylindole-stained root primordia indicated the occurrence of approximately $10 \%$ of cortical cells with a double DNA content (M. Alves-Ferreira, unpublished results).

Upon inoculation of the adventitious root primordia with bacteria, a wave of changes in gene expression was observed, leading to new pattern formation. Cortical cells scattered over the base of the root primordium started to express Sesro; $C y C B 1 ; 1$ and $H 4-1 S r$. The apical root meristem responded in a different way. Sesro; $C y c B 1 ; 1$ expression was not switched on and the H4- $\mathrm{Sr}$ transcripts were no longer detected. This disappearance of $\mathrm{H} 4-\mathrm{SSr}$ transcripts is an intriguing observation, somewhat reminiscent of the phenomenon of loss of apical dominance, and needs to be further investigated.

The consequence of cell cycle gene expression in the cortical cells was visible 2 days after inoculation: globular nodule primordia, consisting of small, dense cells, were formed and surrounding vascular tissues were developing (Fig. 1B). In both regions, Sesro; $C y c B 1 ; 1$ and $H 4-1 S r$ were expressed in a patchy pattern typical for cell cycle phase-specific genes. Per root primordium, often two or more nodule primordia developed and eventually fused. The globular primordia changed form to surround the infection centers (Fig. 1C), and Sesro; $C y c B 1 ; 1$ and $H 4-1 S r$ expression shifted to distal regions. From this stage on, longitudinal sections showed a 
zonation of the central tissue much resembling the zonation in indeterminate nodules with a distal meristem, an infection zone, and a zone of infected plant cells (Fig. 1D-F). The in situ location of Sesro; $C y c B 1 ; 1$ and $H 4-1 S r$ transcripts confirmed the meristematic nature of the distal cell layers and the proximal-distal differentiation direction. In situ hybridizations with an enod 2 probe also revealed that the nodule parenchyma shows a similar proximal-distal differentiation direction (S. Goormachtig, unpublished results). H4-1Sr and Sesro; $C y c B 1 ; 1$ transcripts were also sporadically detected in infected cells of the central tissue. Division of infected cells is typical for determinate nodules (Newcomb et al. 1979) and illustrates the hybrid nature of $S$. rostrata nodule development, with features of both determinate and indeterminate prototypes.

At approximately 8 days post inoculation, Sesro; $C y c B 1 ; 1$ and $H 4-1 S r$ expression faded out, indicating the end of development by division (Fig. 1G). Further nodule growth must result from cell enlargement. However, some histone $\mathrm{H} 4$ and cyclin expression remained observable in peripheral tissues. Divisions in this concentric peripheral meristem may provide cells to the cortical cell layers during expansion of the nodule and/ or alternatively may reflect secondary growth for periderm formation.

Overall, our in situ analysis confirms previous descriptions of $S$. rostrata stem nodule development and adds detailed and precise information on pattern formation in relation to cell division. Our observation of a proximal-distal differentiation direction of the stem nodule does not completely correspond to the radial development (proceeding in all directions from a centrally located infection center) proposed for S. rostrata root nodules by Ndoye et al. (1994). In situ hybridizations of developing root nodules could help to clarify minor differences between root and stem nodule ontogeny.

In conclusion, although mature stem nodules are determinate, their development shows features of indeterminate nodules such as the proximal-distal differentiation and the place of origin (middle-inner cortex). In situ hybridizations with other molecular markers (e.g., nif, leghemoglobin, and early nodulin genes) will be performed to confirm the establishment of functional zones before cessation of meristem activity. Finally, the present study provides a frame for the interpretation of expression patterns of newly isolated $S$. rostrata genes (Goormachtig et al. 1995), involved in the development of stem nodules.

\section{MATERIALS AND METHODS}

\section{Biological material.}

Sesbania rostrata seeds were surface sterilized (Goethals et al. 1989) and germinated, grown, and infected with Azorhizobium caulinodans ORS571 as described by Goormachtig et al. (1995). The plant material was harvested by peeling the root primordia off the stem. For extraction of RNA, material was frozen directly in liquid nitrogen. For in situ hybridization, root primordia were transferred to fixation solutions (see below).

\section{Isolation of nucleic acids.}

RNA was prepared from root primordia as described by Goormachtig et al. (1995). Messenger RNA was separated with the poly(A) Quick mRNA purification kit (Stratagene, La Jolla, CA), following the instructions of the manufacturer. $S$. rostrata genomic DNA was extracted from young leaves as described by Dellaporta et al. (1983).

\section{RT-PCR.}

cDNA was prepared from $1 \mu \mathrm{g}$ of total RNA with the Superscript Preamplification system for First Strand cDNA Synthesis (Gibco BRL, Gaithersburg, MD) according to the instructions provided in the manual of the kit. One tenth of the reaction volume was used per PCR reaction. To isolate a $c d c 2$ gene homolog of $S$. rostrata, a PCR was performed using the primers 5' TCCTGCAGGGAGGG/AIGTTCCIAGCACIGC $3^{\prime}$ and $5^{\prime}$ CAAAGCTTCTG/TTTIGGTTTTAAATCICGATG $3^{\prime}$ covering the regions indicated in Figure $2 \mathrm{~B}$. The PCR consisted of 35 cycles $\left(1 \mathrm{~min}\right.$ at $94^{\circ} \mathrm{C}, 2 \mathrm{~min}$ at $43^{\circ} \mathrm{C}$, and $2 \mathrm{~min}$ at $72^{\circ} \mathrm{C}$ ) and an extension of $10 \mathrm{~min}$ at $72^{\circ} \mathrm{C}$. To isolate a cyclin gene homolog of $S$. rostrata, a nested PCR was performed with, in the first round of PCR, 30 cycles of 2 min at $94^{\circ} \mathrm{C}, 2$ $\min$ at $45^{\circ} \mathrm{C}, 3 \mathrm{~min}$ at $72^{\circ} \mathrm{C}$, and extension of $10 \mathrm{~min}$ at $72^{\circ} \mathrm{C}$, the antisense primer $5^{\prime}$ GACTGCT/CGAAGCAGCAACCAT TGA 3', and the sense primer 5' AGGATGAGG/AGCTATTA CTG/AGTTGA $3^{\prime}$. One tenth of the first PCR was used to perform a second amplification with the same antisense primer as before and the sequence $5^{\prime}$ CTT/GT/ATGGCATG/ CCAAGTATGAAGAA $3^{\prime}$ as sense primer. The same reaction conditions were used as in the first PCR.

The reactions were loaded on a $1.4 \%$ agarose gel and bands of expected size were excised as described by Sambrook et al. (1989). Fragments were rendered blunt ended with the Klenow fragment of DNA polymerase (Boehringer, Mannheim, Germany) and phosphorylated with $\mathrm{T}_{4}$ DNA kinase (Boehringer), according to the protocols described by Sambrook et al. (1989). Subsequently, the DNA fragments were cloned in a pBluescript $\mathrm{KS}(-)$ vector (Stratagene).

\section{cDNA library construction and screening.}

Five micrograms of mRNA derived from infected root primordia, 3 days after inoculation, was used to construct a $\lambda$ Zap cDNA library (Stratagene) as described in the manual from the corresponding kit. A cDNA library containing $2.5 \times 10^{6}$ individual clones from which $8 \%$ were self-ligands was obtained. The cDNA library was screened on Hybond-N filters (Amersham, Aylesbury, U.K.) by standard procedures (Sambrook et al. 1989). ${ }^{32} \mathrm{P}$-labeled probes from the cyclin and $c d c 2$ PCR fragments were generated with the "quick prime" kit (Pharmacia, Uppsala, Sweden). Three rounds of screening were performed to obtain single positive plaques. Next, phages from positive plaques were 'zapped' to their corresponding plasmid form according to the protocol provided by the manufacturer (Stratagene). Plasmid DNA was prepared according to standard procedures (Sambrook et al. 1989). The plasmid containing the full-length $c d c 2$ cDNA was called pCdc2-1 whereas the one containing the last 955 bp of the cyclin was designated pCyc-cd.

\section{$5^{\prime}$ RACE reaction.}

$5^{\prime}$ RACE reactions were performed according to the manufacturer's instructions (Gibco BRL). The antisense primer 5' TTCTTCATACTTGGATGCCATCAG 3' was used to make specific cDNA. The antisense primer $5^{\prime}$ AAGTATAGCTCT 
CATCCTCTCATTGAT 3' was used together with the G-rich sense primer provided with the kit for the PCR reaction. The RACE products were cloned into the pGEMT vector (Promega, Madison, WI).

\section{Southern hybridization.}

Ten micrograms of $S$. rostrata genomic DNA was digested with EcoRI, HindIII, PstI, and XbaI according to the protocols described by Sambrook et al. (1989) and the DNA fragments were separated on a $0.7 \%$ agarose gel. The DNA was transferred to Hybond-N filters (Amersham) and hybridized at $65^{\circ} \mathrm{C}$ following standard procedures (Sambrook et al. 1989). ${ }^{32} \mathrm{P}$-labeled probes were generated as described above. To detect the $c d c 2$ and cyclin genes, pCdc2-1 and pCyc-cd were used, respectively. The hybridization was washed twice for 15 min with $2 \times \mathrm{SSC}(1 \times \mathrm{SSC}$ is $0.15 \mathrm{M} \mathrm{NaCl}$ plus $0.015 \mathrm{M}$ sodium citrate), $0.1 \%$ sodium dodecyl sulfate (SDS); twice for 15 min with $1 \times \mathrm{SSC}, 0.1 \% \mathrm{SDS}$; and once for $15 \mathrm{~min}$ with $0.1 \times \mathrm{SSC}, 0.1 \% \mathrm{SDS}$ at $65^{\circ} \mathrm{C}$. Blots were exposed to Fuji film for 5 days.

\section{In situ hybridization.}

Fresh plant material (noninfected root primordia and stem nodules at different stages of development) was fixed in $4 \%$ paraformaldehyde, $0.25 \%$ glutaraldehyde in $0.1 \mathrm{M}$ cacodylate buffer ( $\mathrm{pH}$ 7.2) overnight at $4^{\circ} \mathrm{C}$, and embedded in paraffin according to Cox et al. (1984). Ten-micrometer sections were cut on a microtome (Reichert-Jung, Nussloch, Germany) and mounted on vectabond-coated slides (Sigma, St. Louis, MO). Sections were taken through the in situ hybridization procedure essentially as described by Angerer and Angerer (1991). ${ }^{35} \mathrm{~S}$ labeled sense and antisense probes were generated with $\mathrm{T}_{7}$ and $\mathrm{T}_{3}$ polymerase (Gibco BRL). The plasmids pCdc2-1, pCyc-cd, and pH4-1 (full-length histone clone) were digested with EcoRI, $B a m \mathrm{HI}$, and EcoRI to create antisense probes and with XhoI, HindIII, and XhoI to produce sense probes, respectively. After hybridization, slides were washed for $1 \mathrm{~h}$ in $2 \times \mathrm{SSC}$ at room temperature and $1 \mathrm{~h}$ in $0.1 \times \mathrm{SSC}$ at $65^{\circ} \mathrm{C}$. Photographs were taken with a Diaplan microscope equipped with bright- and dark-field optics (Leitz, Wetzlar, Germany). Double exposures were taken as described by Drews et al. (1991). In situ hybridizations on methacrylate-embedded material were performed essentially according to Kronenberger et al. (1993). A detailed protocol will be described elsewhere (M. Alves-Ferreira, J. de Almeida Engler, M. Van Montagu, and G. Engler, in preparation). For each gene, control in situ hybridizations were performed with their corresponding sense probes. In none of the cases was expression above background observed.

\section{DNA sequence analysis.}

DNA sequence procedures were carried out essentially as described by Sanger et al. (1977). DNA sequence data were assembled and analyzed with the GCG package (version 7; Genetics Computer Group, Madison, WI). The percentage of similarity between sequences was determined with the GAP program of GCG.

\section{ACKNOWLEDGMENTS}

We thank Bernard Dreyfus (ORSTOM, Dakar, Senegal) for providing Sesbania rostrata seeds; Wilson Ardiles, Annick De Keyser, and Hilde
Van Den Daele for help with DNA sequencing; Karel Spruyt, Christiane Germonprez, and Rebecca Verbanck for lay-out and photographs; Martine De Cock for help with the manuscript; and Peter Mergaert, Dirk Inzé, Nathalie Barthels, and Vladimir Mironov for helpful comments. The research was supported by grants from the Belgian Programme on Interuniversity Poles of Attraction (Prime Minister's Office, Science Policy Programming, No. 38) and in part by the European Communities' BIOTECH Programme, as part of the Project of Technological Priority 1993-1996, and the Human Capital and Mobility Programme (CHRXCT94-0656). M. Alves-Ferreira is indebted to the Coordenação de Aperfeiçoamento de Pessoal de Nível Superior (CAPES 1328/94-4) for predoctoral fellowships. G. Engler is a Research Engineer of the Institut National de la Recherche Agronomique (France). S. Goormachtig was a Research Assistant and M. Holsters is a Research Director of the Fund for Scientific Research (Flanders).

\section{LITERATURE CITED}

Amon, A., Tyers, M., Futcher, B., and Nasmyth, K. 1993. Mechanisms that help the yeast cell cycle clock tick: G2 cyclins transcriptionally activate G2 cyclins and repress G1 cyclins. Cell 74:993-1007.

Angerer, L. M., and Angerer, R. C. 1991. Localization of mRNAs by in situ hybridization. Methods Cell Biol. 35:37-71.

Cox, K., DeLeon, D. V., Angerer, L. M., and Angerer, R. C. 1984. Detection of mRNAs in sea urchin embryos by in situ hybridization using asymmetric RNA probes. Dev. Biol. 101:485-502.

Dellaporta, S. L., Wood, J., and Hicks, J. B. 1983. A plant DNA minipreparation: version II. Plant Mol. Biol. Rep. 1:19-21.

Drews, G. N., Bowman, J. L., and Meyerowitz, E. M. 1991. Negative regulation of the Arabidopsis homeotic gene AGAMOUS by the APETALA2 product. Cell 65:991-1002.

Dreyfus, B., Garcia, J. L., and Gillis, M. 1988. Characterization of Azorhizobium caulinodans gen. nov., sp. nov., a stem-nodulating nitrogen-fixing bacterium isolated from Sesbania rostrata. Int. J. Syst. Bacteriol. 38:89-98.

Duhoux, E. 1984. Ontogénèse des nodules caulinaires du Sesbania rostrata (légumineuses). Can. J. Bot. 62:982-994.

Duhoux, E., and Dreyfus, B. L. 1982. Nature des sites d'infection par le Rhizobium de la tige de la légumineuse Sesbania rostrata Brem. C. R. Hebd. Séances. Acad. Sci. Paris 294:407-411.

Fobert, P. R., Coen, E. S., Murphy, G. J. P., and Doonan, J. H. 1994. Patterns of cell division revealed by transcriptional regulation of genes during the cell cycle in plants. EMBO J. 13:616-624.

Franssen, H. J., Vijn, I., Yang, W. C., and Bisseling, T. 1992. Developmental aspects of the Rhizobium-legume symbiosis. Plant Mol. Biol. 19:89-107.

Franssen, H., Yang, W.-C., Bakker, J., Hirt, H., and Bisseling, T. 1994. Isolation and characterization of cDNA clones of cell cycle specific genes from pea. Pages 152-157 in: Proc. Eur. Nitrogen Fixation Conf., 1st. G. B. Kiss and G. Endre, eds. Officina Press, Szeged, Hungary.

Glotzer, M., Murray, A. W., and Kirschner, M. W. 1991. Cyclin is degraded by the ubiquitin pathway. Nature (London) 349:132-138.

Goethals, K., Gao, M., Tomekpe, K., Van Montagu, M., and Holsters, M. 1989. Common nodABC genes in Nod locus 1 of Azorhizobium caulinodans: Nucleotide sequence and plant-inducible expression. Mol. Gen. Genet. 219:289-298.

Goormachtig, S., Valerio-Lepiniec, M., Szczyglowski, K., Van Montagu, M., Holsters, M., and de Bruijn, F. J. 1995. Use of differential display to identify novel Sesbania rostrata genes enhanced by Azorhizobium caulinodans infection. Mol. Plant-Microbe Interact. 8:816-824.

Goormachtig, S., Van Montagu, M., and Holsters, M. 1996. Nucleotide sequence of two histone H4 cDNAs of Sesbania rostrata (Accession numbers Z79637 and Z79638). Plant Physiol. 112:1398.

Hanks, S. K., Quinn, A. M., and Hunter, T. 1988. The protein kinase family: conserved features and deduced phylogeny of the catalytic domains. Science 241:42-52.

Hata, S., Kouchi, H., Suzuka, I., and Ishii, T. 1991. Isolation and characterization of cDNA clones for plant cyclins. EMBO J. 10:26812688.

Hemerly, A. S., Ferreira, P. C. G., de Almeida Engler, J., Van Montagu, M., Engler, G., and Inzé, D. 1993. cdc2a expression in Arabidopsis thaliana is linked with competence for cell division. Plant Cell 5: 1711-1723. 
Hong, Z., Miao, G.-H., and Verma, D. P. S. 1993. p34 ${ }^{\text {cdc2 }}$ protein kinase homolog from mothbean (Vigna aconitifolia). Plant Physiol. 101: 1399-1400.

Jacobs, T. W. 1995. Cell cycle control. Ann. Rev. Plant Physiol. Plant Mol. Biol. 46:317-339.

Kronenberger, J., Desprez, T., Höfte, H., Caboche, M., and Traas, J. 1993. A methacrylate embedding procedure developed for immunolocalization on plant tissues is also compatible with in situ hybridization. Cell Biol. Int. 17:1013-1021.

Martinez, M. C., Jørgensen, J.-E., Lawton, M. A., Lamb, C. J., and Doerner, P. W. 1992. Spatial pattern of $c d c 2$ expression in relation to meristem activity and cell proliferation during plant development. Proc. Natl. Acad. Sci. USA 89:7360-7364.

Miao, G.-H., Hong, Z., and Verma, D. P. S. 1993. Two functional soybean genes encoding $\mathrm{p} 34^{\text {cdc2 }}$ protein kinases are regulated by different plant developmental pathways. Proc. Natl. Acad. Sci. USA 90:943-947.

Mikami, K., and Iwabuchi, M. 1993. Regulation of cell cycle-dependent gene expression. Pages 51-68 in: Control of Plant Gene Expression. D. P. S. Verma, ed. CRC, Boca Raton, FL.

Ndoye, I., de Billy, F., Vasse, J., Dreyfus, B., and Truchet, G. 1994. Root nodulation of Sesbania rostrata. J. Bacteriol. 176:1060-1068.

Newcomb, W. 1976. A correlated light and electron microscopic study of symbiotic growth and differentiation in Pisum sativum root nodules. Can. J. Bot. 54:2163-2186.

Newcomb, W., Sippell, D., and Peterson, R. L. 1979. The early morphogenesis of Glycine max and Pisum sativum root nodules. Can. J. Bot. 57:2603-2616.

Nigg, E. A. 1995. Cyclin-dependent protein kinases: Key regulators of the eukaryotic cell cycle. BioEssays 17:471-480.

Patriarca, E. J., Taté, R., Fedorova, E., Riccio, A., Defez, R., and Iaccarino, M. 1996. Down-regulation of the Rhizobium ntr system in the determinate nodule of Phaseolus vulgaris identifies a specific developmental zone. Mol. Plant-Microbe Interact. 9:243-251.

Pines, J. 1994. Protein kinases and cell cycle control. Semin. Cell Biol. 5:399-408.

Renaudin, J.-P., Savouré, A., Philippe, H., Van Montagu, M., Inzé, D., and Rouzé, P. Characterization and classification of plant cyclin sequences related to A- and B-type cyclins. In: Plant Cell Division. D. Francis, D. Dudits, and D. Inzé, eds. Portland, London, UK. (In press.)
Renaudin, J.-P., Doonan, J. H., Freeman, D., Hashimoto, J., Hirt, H., Inzé, D., Jacobs, T., Kouchi, H., Rouzé, P., Sauter, M., Savouré, A., Sorrell, D. A., Sundaresan, V., and Murray, J. A. H. 1996. Plant cyclins: A unified nomenclature for plant A-, B- and D-type cyclins based on sequence organisation. Plant Mol. Biol. 32:1003-1018.

Sambrook, J., Fritsch, E. F., and Maniatis, T. A. 1989. Molecular Cloning: A Laboratory Manual. 2nd ed. Cold Spring Harbor Laboratory, Cold Spring Harbor, NY.

Sanger, F., Nicklen, S., and Coulson, A. R. 1977. DNA sequencing with chain-terminating inhibitors. Proc. Natl. Acad. Sci. USA 74:54635467.

Setiady, Y. Y., Sekine, M., Hariguchi, N., Yamamoto, T., Kouchi, H., and Shinmyo, A. 1995. Tobacco mitotic cyclins: Cloning, characterization, gene expression and functional assay. Plant J. 8:949-957.

Shaul, O., Mironov, V., Burssens, S., Van Montagu, M., and Inzé, D. 1996. Two Arabidopsis cyclin promoters mediate distinctive transcriptional oscillation in synchronized tobacco BY-2 cells. Proc. Natl. Acad. Sci. USA 93:4868-4872.

Spencer-Barreto, M. M., Cottignies, A., Chamel, A., and Duhoux, E. 1995. Caractéristiques cytophysiologiques des ébauches racinaires adventives de la tige de Sesbania rostrata Brem (Leguminosae). Acta Bot. Gallica 142:763-771.

Spencer-Barreto, M. M., and Duhoux, E. 1994. Root-to-shoot primordium conversion on Sesbania rostrata Brem. stem explants. J. Exp. Bot. 45:1851-1857.

Taté, R., Patriarca, E. J., Riccio, A., Defez, R., and Iaccarino, M. 1994. Development of Phaseolus vulgaris root nodules. Mol. Plant-Microbe Interact. 7:582-589.

Tyers, M., Tokiwa, G., Nash, R., and Futcher, B. 1992. The Cln3-Cdc28 kinase complex of $S$. cerevisiae is regulated by proteolysis and phosphorylation. EMBO J. 11:1773-1784.

Tsien, H. C., Dreyfus, B. L., and Schmidt, E. L. 1983. Initial stages in the morphogenesis of nitrogen-fixing stem nodules of Sesbania rostrata. J. Bacteriol. 156:888-897.

Yang, W.-C., de Blank, C., Meskiene, I., Hirt, H., Bakker, J., van Kammen, A., Franssen, H., and Bisseling, T. 1994. Rhizobium Nod factors reactivate the cell cycle during infection and nodule primordium formation, but the cycle is only completed in primordium formation. Plant Cell 6:1415-1426. 